\title{
MELHORAMENTO DO TRIGO. X. ESTIMATIVAS DA HERDABILIDADE E CORRELACCÕES ENTRE TOLERÂNCIA À TOXICIDADE DE ALUMÍNIO E PRODUÇÃO DE GRÃOS COM OUTROS CARACTERES AGRONÔMICOS EM TRIGO ${ }^{(1)}$
}

CARLOS EDUARDO DE OLIVEIRA CAMARGO, Seção de Arroz e Cereais de Inverno, Instituto Agronômico.

\begin{abstract}
RESUMO
Visando estimar a herdabilidade para várias caractericticas da planta de trigo (tolerância ao Al3+, altura, produção de grãos, número de espigas, número de espiguetas e de grãos por espiga, número de grãos por espigueta, peso de cem grãos e comprimento da espiga), bern como as correlações entre produção de gráos com sete caracteres agronômicos e aquelas entre tolerância ao alumínio com produção de grãos, altura das plantas e número de grãos por espigueta (fertilidade da espiga), foram efetuados cruzamentos entre o cultivar de porte semi-anāo Alondra S-46, e os de porte alto 'TAC-5', 'BH-1146' e 'C-3'. Plântulas representando os pais, as gerações $F_{1}$ e $F_{2}$ e os retrocruzamentos para ambos os pais foram testados para a reação a $6 \mathrm{mg} /$ litro de $\mathrm{Al} 3+$ em solução nutritiva. As plantas, devidamente identificadas, foram transplantadas em número de quatro por vaso, empregando-se no total 500 vasos dispostos em quatro blocos ao acaso. Os dados referentes à produção de grãos e a outros caracteres agronômicos forłm obtidos de plantas individuais. Os valores da herdabilidade no sentido
\end{abstract}

(1) Com verba suplementar do Acordo do Trigo entre as Cooperativas de Produtores Rurais do Vale do Paranapanema e a Secretaria de Agricultura e Abastecimento, por meio do Instituto Agronômico. Recebido para publicação a $1^{\circ}$ de setembro de 1983.

(2) Com bolsa de suplementação do CNPq. 
restrito para comprimento da espiga, número de grãos por espiga, peso de cem grãos e altura da planta foram 0,$885 ; 0,748 ; 0,760$ e 0,720 respectivamente, e de 0,413 e 0,588 para número de espigas por planta e de espiguetas por espiga. Para os demais caracteres estudados, os valores estimados foram baixos, variando de 0,072 a 0,224. Esses resultados indicaram que grande parte da variabilidade genética total para comprimento da espiga, número de grãos por espiga, peso de cem grãos e altura das plantas está associada a uma ação aditiva dos genes. Nas populacoóes estudadas, a caracteristica produção de grãos foi correlacionada significativamente com todos os caracteres agronômicos estudados com exceção do caráter número de espiguetas por espiga. Nessas populaçōes, a tolerância ao alumínio não foi associada com altura das plantas (com exceção da Alondra S-46 x IAC-5), produção de grãos e número de grãos por espigueta, sugerindo que seria possivel selecionar plantas tolerantes ao $\mathrm{Al}^{3+}$, de porte médio, com maior fertilidade da espiga e com o potencial produtivo do cultivar Alondra-S-46.

\section{INTRODUĢĀO}

A toxicidade do alumínio é um dos fatores de maior limitação à produção de trigo em solos ácidos (13). De forma geral, os cultivares adaptados para essas condiçōes são altos, sensíveis ao ‘̇camamento, e apresentam poucas flores férteis e grãos por espiga, resultando em baixa produção de grãos.

Os cultivares de trigo semi-anões desenvolvidos principalmente no Centro Internacional de Melhoramento de Milho e Trigo (CIMMYT), México, aumentaram em muitos países a produtividade desse cereal mediante maior resistência ao acamamento e eficiência fotossintética (12). Entretanto, tais cultivares não são adaptados a solos ácidos com altos níveis de aluminio trocável ou solúvel.

Diferenças observadas para a tolerância ao alumínio entre cultivares de uma mesma espécie sugerem a possibilidade de aumentar a tolerância ao alumínio dos cultivares comerciais pelo melhoramento genético (8).

Resultados obtidos por CAMARGO et alii (2) mostraram que seria possivel selecionar plantas que combinavam tolerância ao $\mathrm{Al}$, porte semi-anão e alto potencial produtivo, requerendo, para isso, grandes populaçōes $F_{2}$ para assegurar maior freqüência de recombinantes desejáveis.

A herdabilidade de um caráter agronômico descreve a extensão por que ele é transmitido de uma geração para outra, porém ela é dependente do ambiente para o qual os indivíduos estão sendo selecionados $(6,10)$.

O estudo das associações entre os componentes de frodução de uma população híbrida permite saber se os componentes são geneticamente dependentes ou independentes, isto é, se tendem ou não em permanecer associados nas progênies durante os șucessivos ciclos de seleção $(\mathbf{7}, \mathbf{9})$. 
O presente trabalho tem por objetivo estudar a herdabilidade em sentido restrito para oito caracteres agronômicos, e as associações entre a tolerância a $6 \mathrm{mg} /$ litro de $\mathrm{Al}^{3+}$ em solução nutritiva e a produção de grãos com caracteres agronômicos, a partir de populaçōes híbridas de trigo originárias de cruzamentos entre três cultivares de porte alto e tolerantes ao alumínio e um cultivar de porte baixo e sensível ao alumínio.

\section{MATERIAL E METODOS}

Dos quatro cultivares estudados - Alondra S-46 $\left(\mathrm{P}_{\mathrm{i}}\right)$, IAC-5 $\left(\mathrm{P}_{2}\right)$, C-3 $\left(\mathrm{P}_{3}\right)$ e BH-1146 $\left(\mathrm{P}_{4}\right)$ - C-3, BH-1146 e IAC-5 são de porte alto e tolerantes a $6 \mathrm{mg} /$ litro de $\mathrm{Al}^{3+}$ na solução nutritiva, ao passo que o Alondra S-46 é sensível a essa concentração de alumínio (5).

Foram obtidas as sementes $F_{1}$ e $F_{z}$ dos cruzamentos Alondra $\mathrm{S}-46$ $\times$ IAC-5 $\left(\mathrm{P}_{1} \times \mathrm{P}_{2}\right)$, Alondra S-46 x C-3 $\left(\mathrm{P}_{1} \times \mathrm{P}_{3}\right)$ e Aiondra S-46 x BH-1146 $\left(\mathrm{P}_{1} \times \mathrm{P}_{4}\right)$, como também as sementes dos retrocruzamentos para ambos os pais, a saber: $\left(\mathrm{P}_{1} \times \mathrm{P}_{2}\right) \times \mathrm{P}_{1},\left(\mathrm{P}_{1} \times \mathrm{P}_{2}\right) \times \mathrm{P}_{2},\left(\mathrm{P}_{1} \times \mathrm{P}_{3}\right) \times$ $\mathrm{P}_{1},\left(\mathrm{P}_{1} \times \mathrm{P}_{3}\right) \times \mathrm{P}_{3},\left(\mathrm{P}_{1} \times \mathrm{P}_{4}\right) \times \mathrm{P}_{1} \mathrm{e}\left(\mathrm{P}_{1} \times \mathrm{P}_{4}\right) \times \mathrm{P}_{4}$.

Os pais, $F_{1}$ 's, $F_{2}$ 's e retrocruzamentos para ambos os pais foram testados para tolerância a $6 \mathrm{mg} /$ litro de $\mathrm{Al}^{3+}$, conforme niétodo já publicađo $(5,11)$.

Foram testadas em soluções nutritivas contendo $6 \mathrm{mg} /$ litro de $\mathrm{Al}^{3+}$, 80 sementes uniformes de cada cultivar utilizado como progenitor e de cada cruzamento em geração $F_{1}$, e 160 sementes de cada cruzamento em geração $F_{2}$ e de cada retrocruzamento. Após a avaliação da tolerância ao $\mathrm{Al}^{3 \div}$, as plântulas foram transplantadas para vasos preenchidos com solo adubado e sem alumínio trocável colocados no telado contra o ataque de pássaros, no Centro Experimental de Campinas. Anteriormente ao transplante, foram retiradas amostras compostas do soio dos vasos, e cujos resultados analíticos ${ }^{(3)}$ foram os seguintes:

Determinaçōes

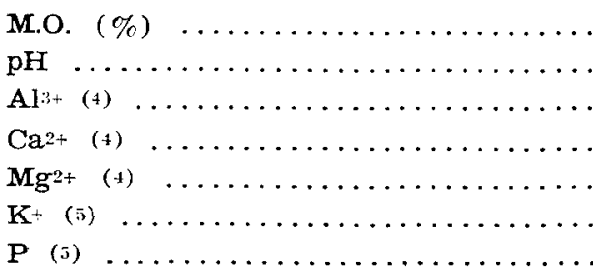

Teores dos elementos no solo estudado

$$
\begin{array}{r}
8,1 \\
6,6 \\
0,0 \\
10,4 \\
4,0 \\
200 \\
100+
\end{array}
$$

(3) Análise efetuada pela Seção de Fertiildade do Solo, Instituto Agronômico.

(4) e.mg. $/ 100 \mathrm{mI}$ de T.F.S.A. Teores trocáveis.

(5) $\mu \mathrm{g} / \mathrm{ml}$ de T.F.S.A. 
As plântulas devidamente identificadas quanto à tolerância a $6 \mathrm{mg} / \mathrm{li}$ tro de $\mathrm{Al}^{3 \div}$, em solução nutritiva, foram plantadas eqüidistantes uma da outra em número de quatro por vaso.

O delineamento estatístico empregado foi blocos ao acaso com 16 tratamentos, incluindo os quatro pais, três $F_{1}$ 's, três $F_{2}$ 's e seis retrocruzamentos. Cada repetição foi formada por cince vasos de cada progenitor e híbrido em geração $F_{1}$ e por dez vasos de cada híbrido em geração $F_{2}$ e para cada retrocruzamento. $O$ conjunto das quatro repetições foi constituido de 500 vasos de plástico preto de aproximadamente $25 \mathrm{~cm}$ de altura e $20 \mathrm{~cm}$ de diâmetro. Os vasos foram distribuídos distantes um do outro $10 \mathrm{~cm}$ na linha e $40 \mathrm{~cm}$ entre linhas. Foi plantada uma linha adicional de vasos contornando o experimento, visando minimizar os efeitos de bordadura.

Os dados, coletados na base de plantas individuais, foram os seguintes:

Tolerância ao alumínio - Considerada como crescimento, em milín metro, da raiz primária central em 72 horas na solução nutritiva completa, após um tratamento de 48 horas em solução nutritiva contendo $6 \mathrm{mg} /$ litro de $\mathrm{Al}^{3+}$.

Altura da planta - Medida, em centímetros, do nível do solo até o ápice das espigas, excluindo as aristas.

Espigas por planta - Considerado apenas o número de colmos com espigas férteis.

Produção de grãos - Peso, em gramas, da produção total de grãos de cada planta.

Comprimento da espiga - Medida, em centímetros, da espiga do colmo principal, excluindo as aristas.

Espiguetas - Computado o número de espiguetas do colmo principal. cipal.

Grãos por espiga - Número total de grãos da espisa do colmo prin-

Grãos por espigueta - Número resultante da divisão do total de grãos da espiga principal pelo total de espiguetas da mesma espiga.

Peso de cem grãos - Peso, em gramas, de cem grãos coletados ao acaso na produção total da planta.

Todos os caracteres estudados foram sujeitos à análise de variância, e o teste $\mathrm{F}$ foi utilizado para determinar diferenças significativas. A média de cada genótipo em cada repetição foi usada na analise de variância, cujos efeitos de geraçāo foram divididos em compunentes para detectar diferenças dentro de e entre gerações. A estimativa da herdabilidade em sentido restrito foi calculada pela regressão da média dos $F_{2}$ em cada repetição sobre os respectivos $F_{1}$ segundo FALCONER (6). 
As correlações fenotípicas, genotípicas e ambientes foram usadas para estimar o grau de associação entre a produção de grãos e sete outros caracteres agronômicos para cada uma das três populações $\left(\mathrm{P}_{1} \mathrm{x}\right.$ $\mathrm{P}_{2}, \mathrm{P}_{1} \times \mathrm{P}_{3}$ e $\left.\mathrm{P}_{1} \times \mathrm{P}_{4}\right)$. Foram também calculadas as correlações fenotípicas e ambientes entre a tolerância ac alumínio e produção de grãos, altura e número de grãos por espigueta. Como sugerido por FALCONER (6), as correlações usando dados de $F_{1}$ foram consideradas ambientes, aquelas com dados de $F_{2}$, fenotipicas, e as correlaçōes genéticas foram calculadas pela seguinte fórmula:

$$
r_{F}=\sqrt{\mathrm{H}_{x}} \sqrt{\mathrm{H}_{y}} r_{G}+\sqrt{E_{x}^{-}} \sqrt{\mathrm{H}_{y}^{-}} r_{\Lambda}
$$

onde: $r_{F}=$ correlaçāo fenotípica entre os caracteres $x \notin y: r_{G}=$ correlação genotípica entre $\mathrm{x}$ e $\mathrm{y} ; \mathrm{r}_{\mathrm{A}}=$ correlação ambiente entre $\mathrm{x}$ e $\mathrm{y}$; $\mathrm{H}=$ herdabilidade em sentido restrito com índice $\mathrm{x}$ ou $\mathrm{y}$ de acordo com o caráter $\mathrm{E}=1-\mathrm{H}$, também com índices de acordo com o caráter.

\section{RESULTADOS E DISCUSSÃO}

As análises de variância para comprimento da raiz (tolerância ao $\left.\mathrm{Al}^{3-1}\right)$, comprimento da espiga, número de espiguetas e de grãos por espiga, peso de cem grãos, número de grãos por espigueta, altura das plantas, número de espigas por planta e produção de grãos encontram-ş no quadro 1 , e, as médias de cada genótipo para cada um dos caracteres estudados, no quadro 2.

Aplicando o teste de Tukey a 5\% para a comparação entre o comprimento da raiz, após um período de 72 horas em solução nutritiva completa, seguido de um crescimento de 48 horas em solução contendo $6 \mathrm{mg} /$ litro de $\mathrm{Al}^{3+}$, verificou-se que o 'Alondra $\mathrm{S}-46$ ' foi sensivel a essa concentração de $\mathrm{Al}^{3+}$, diferindo significativamente dos cultivares tolerantes IAC-5, C-3 e BH-1146, que, por sua vez, não diferiram entre si. Não foram detectadas diferenças significativas entre os $F_{1}$ 's, $R C_{1}$ 's e $R_{2}$ 's em relação à tolerância ao $\mathrm{Al}^{3+}$. Em geração $\mathrm{F}_{2}$ o híbrido Alondra $\mathrm{S}-46$ $\mathrm{x}$ IAC-5 foi o menos tolerante, diferindo do hibrido Alondra S-46 x C-3, que foi o mais tolerante, porém não do híbrido Alondra S-46 x BH-1145.

Em relação ao comprimento da espiga, o 'C-3' apresentou as espigas mais compridas, diferindo significativamente dos cultivares Alondra S-46, IAC-5 e BH-1146. Este apresentou as espigas mais curtas, diferindo significativamente dos demais. O híbrido Alondra S-46 x C-3 em geração $F_{1}$ e $F_{2}$ diferiu dos demais, com as espigas mais compridas. $O$ hibrido (Alondra S-46 x C-3) x Alondra S-46 apresentou espigas mais longas que as do híbrido (Alondra $\mathrm{S}-46 \times \mathrm{IAC}-5$ ) $\times$ Alondra $\mathrm{S}-46$, não diferindo deste, porém diferindo das do híbrido (Alondra S-46 x BH-1146) $x$ Alondra S-46. O híbrido (Alondra S-46 x IAC-5) x IAC-5 apresentou espigas mais compridas que os demais, não diferindo do hibrido (Alondra S-46 x C-3) x C-3, porém diferindo do (Alondra S-46 x BH-1146) x $\mathrm{BH}-1146$. 


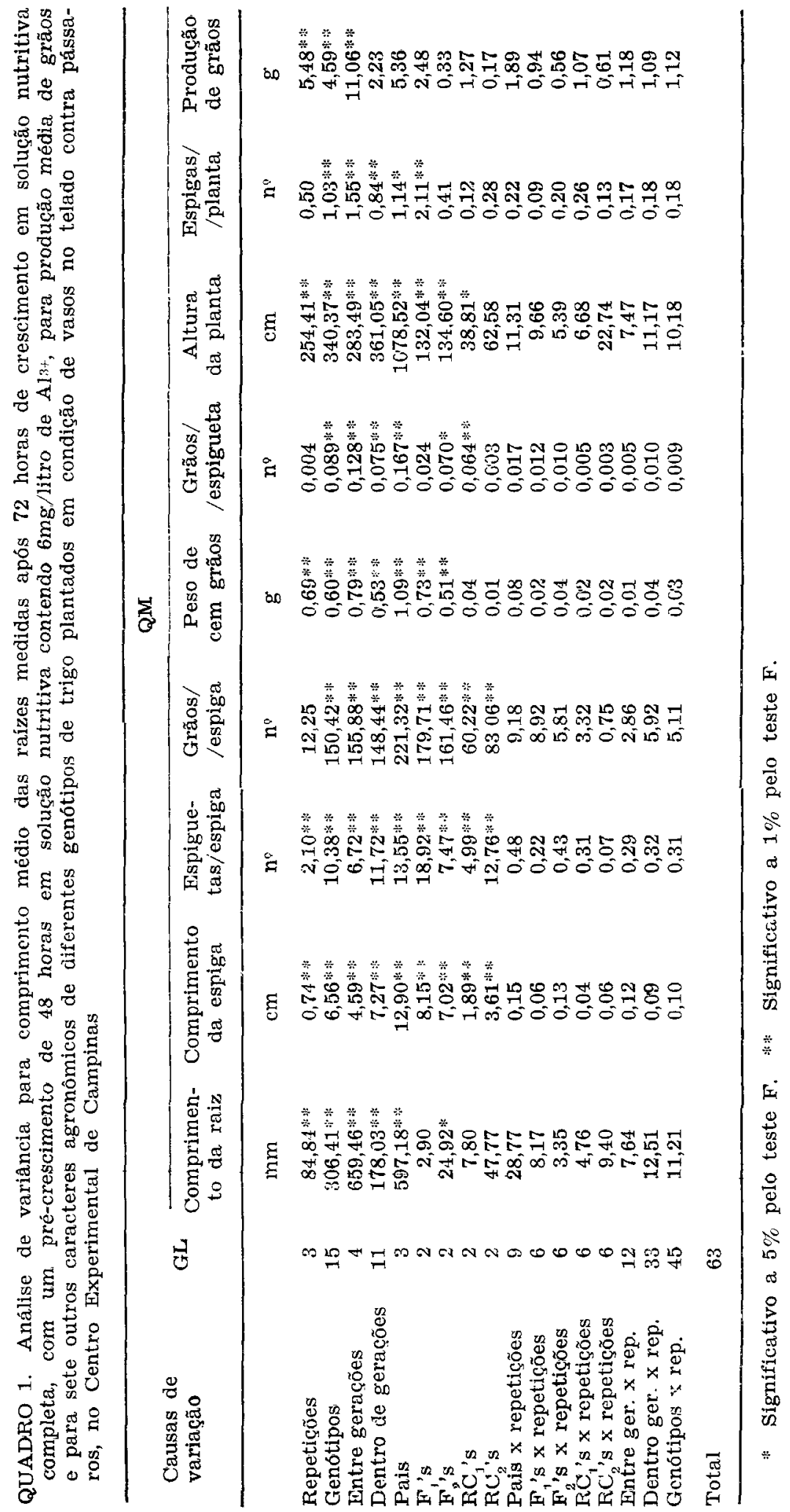




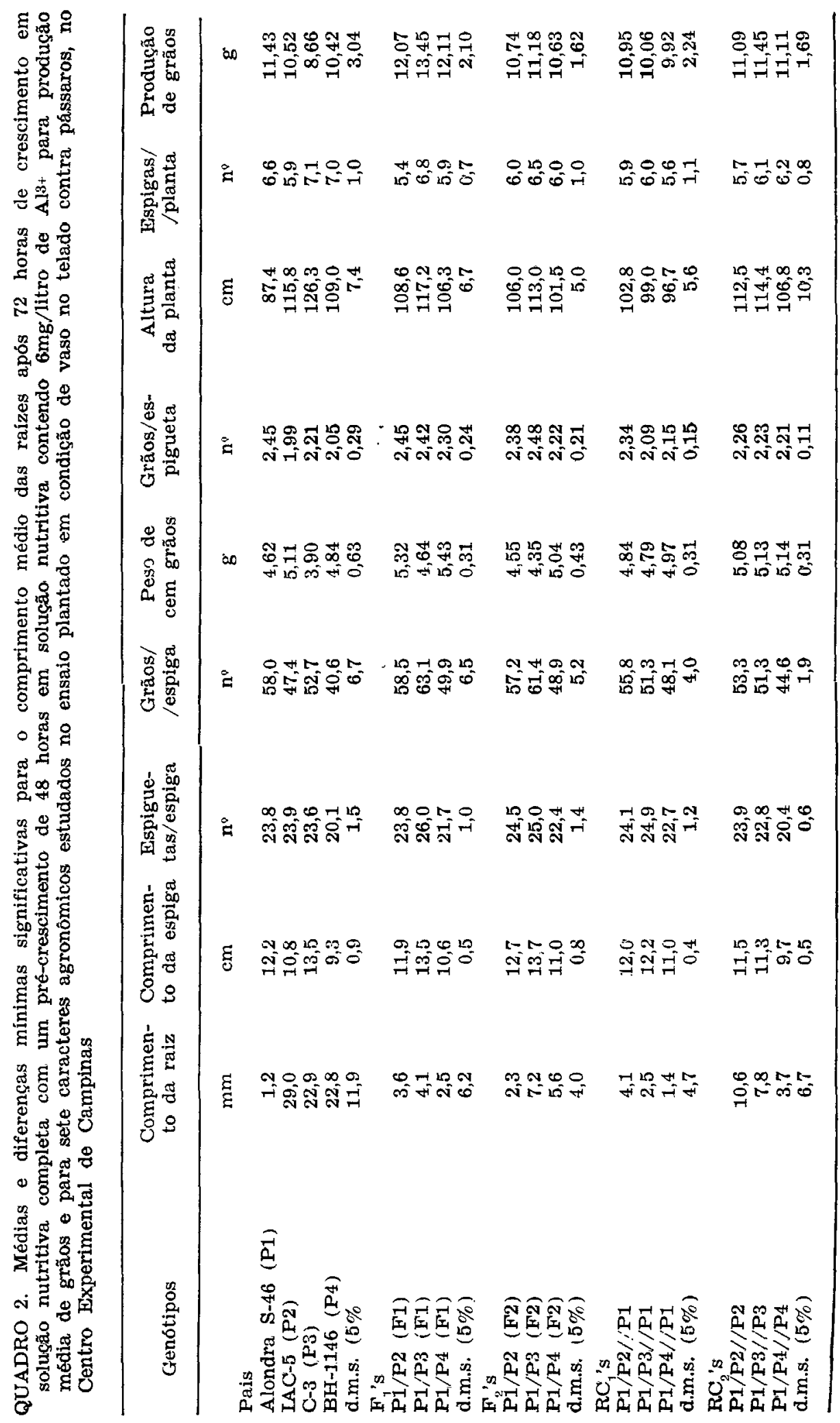


Os cultivares Alonđra S-46, IAC-5 e C-3 não diferiram entre si em relação ao número de espiguetas por espiga, mas os três apresentaram mais espiguetas por espiga do que o BH-1146. O hibrido Alondra S-4b x C-3 em geração $F_{1}$ e $F_{2}$ apresentou o maior número de espiguetas por espiga. O genótipo (Alondra S-46 x C-3) x Alondra S-46 mostrou mais espiguetas por espiga do que o (Alondra S-46 x BH-1146) x Alondra S-46, diferindo significativamente deste, porém não diferindo do (Alondra S-46 x IAC-5) x Alondra S-46. O hibrido (Alondra S-46 x IAC-5) $x$ IAC-5 foi o que apresentou maior número de espiguetas por espiga em relação aos demais retrocruzamentos para o pai de porte alto.

Considerando o número de grãos por espiga, 'Alondra S-46' mostrou maior índice, diferindo significativamente dos cultivares IAC-5 e BH-1146, porém não do C-3. O híbrido Alondra $S-46$ x C-3 em geração $F_{1}$ e $F_{2}$ diferiu do híbrido Alondra S-46 x BH-1146, que apresentou o menor número de grãos por espiga, não diferindo, porém, do híbrido Alondra S-46 x IAC-5. O germoplasma (Alondra S-46 x IAC-5) x Alondra S-46 mostrou maior número de grãos por espiga, diferindo dos demais $\mathrm{RC}_{1}$ 's. Entre os $\mathrm{RC}_{2}$ 's, destacou-se o (Alondra S-46 x IAC-5) x IAC-5.

O cultivar IAC-5 foi o que apresentou grãos mais pesados, diferindo, porém, somente do C-3. O híbrido Alondra S-46 x BH-1146, em geração $\mathrm{F}_{1}$, mostrou grãos mais pesados do que os híbridos Alondra $\mathrm{S}-46 \mathrm{x}$ IAC-5 e Alondra S-46 x C-3, porém somente diferiu estaiisticamente do segundo. Entre os híbridos em geração $F_{2}$, o Alondra S-46 x BH-1146 foi o que apresentou grãos mais pesados, diferindo significativamente dos demais. Não foram detectadas diferenças significativas em relação ao peso de cem grãos para os retrocruzamentos ( $\mathrm{RC}_{1}$ 's e $\mathrm{RC}_{2}$ 's).

Considerando o número de grãos por espigueta, 'Alondra S-46' sobrepujou os demais, diferindo significativamente dos cultivares IAC-5 e $\mathrm{BH}-1146$, porém não do C-3. Entre os $\mathrm{F}_{1}$ 's e $\mathrm{RC}_{2}$ 's não foram observadas diferenças significativas em relação a esse parâmetrci. $O$ genótipo Alondra S-46 x C-3 em geração $F_{2}$ apresentou maior número de grãos por espigueta do que os demais $F_{2}$, diferindo significativamente, porém, do híbrido Alondra S-46 x BH-1146, mas não do Alondra S-46 x IAC-5. O genótipo (Alondra S-46 x IAC-5) x Alondra S-46 diferiu dos demais $\mathrm{RC}_{1}$ 's, com o maior número de grãos por espigueta.

O 'Alondra S-46' apresentou-se como o de menor aitura, diferindo significativamente dos demais, e o 'C-3' foi o mais alto. $\mathrm{O}$ hibrido Alondra $S-46 \times C-3$, em geração $F_{1}$ e $F_{2}$, teve as plantas mais altas, diferindo significativamente dos demais. Não se detectaram diferenças significativas para altura das plantas nos $\mathrm{RC}_{1}$ 's e $\mathrm{RC}_{2}$ 's.

Os cultivares C-3 e BH-1146 mostraram maior número de espigas por planta, diferindo significativamente do IAC-5, porém não do 'Alondra S-46'. Entre os híbridos em geração $\mathrm{F}_{1}$, destacou-se Alondra S-46 x C-3, com mais espigas por planta, diferindo significativamente dos outros 
dois. Não houve diferenças significativas entre os $F_{2}$ 's, $R C_{1}$ 's e $R C_{2}$ 's em relação ao número de espigas por planta.

Em relação à média de produção de grãos, não foram detectadas diferenças significativas entre os cultivares pais, $F_{1}$ 's , $F_{2}$ 's e retrocruzamentos, apesar de as médias das populações $F_{1}$ serem superiores às médias de ambos os pais, evidenciando heterose para esse caráter. Esses resultados também foram encontrados por JOHNSON et alii (9) e CAMARGO et alii $(\mathbf{1}, \mathbf{3}, \mathbf{4})$ que afirmaram haver grande influência do ambiente sobre a produção de grãos de plantas individuais mesmo dentro de condiçốes de preciso espaçamento das plantas.

As estimativas da herdabilidade em sentido restrito $\left(\mathrm{H}_{\mathrm{xS}}\right)$ para oito caracteres estudados, derivadas de dados obtidos nas geraçōes $F_{1}$ e $F_{2}$, encontram-se no quadro 3 .

QUADRO 3. Estimativas da herdabilidade em sentido restrito ( $\mathrm{H}_{\mathrm{NS}}$ ) para todos os caracteres agronomicos estudados, derivadas de dados obtidos nas quatro repetiçōes para os $\mathrm{F}_{1}$ 's e $\mathrm{F}_{2}$ 's de cruzamentos entre Alondra $\mathrm{S}-46$, cultivar de trigo de origem mexicana de alto potencial produtivo, e três cultivares brasileiros

Caracteres agronômicos

Comprimento da espiga $(\mathrm{cm})$

Espiguetas/espiga $\left(\mathrm{n}^{\circ}\right)$

Grãos/espiga ( $\left.n^{\circ}\right)$

Grãos/espigueta $\left(n^{\circ}\right)$

Peso de cem grãos (g)

Espigas/planta $\left(\mathbf{n}^{\circ}\right)$

Altura da planta $(\mathrm{cm})$

Produção de grãos (g)

$$
\mathrm{H}_{\mathrm{xis}}(*)
$$

(*) Estimativa pela regressão do $\mathrm{F}_{2}$ sobre $\circ \mathrm{F}_{1}$, proposto por FALCONER (6).

O valor estimado para a herdabilidade em sentido restrito para comprimento da espiga, número de grãos por espiga, peso de cem grãos e altura da planta foi alto; para número de espigas por planta e de espiguetas por espiga, os valores foram médios, e, para os caracteres número de grãos por espigueta e produção de grãos, baixos. Esses resultados indicam que grande parte da variabilidade genética tota! para comprimento da espiga, número de grãos por espiga, peso de cem grãos e altura da planta está associada a uma ação aditiva dos genes ou é 
devida a genes que se comportam de maneira aditiva. Indicam, ainda, que seleçōes para esses caracteres seriam efetivas nas gerações $F_{2}$ ou $F_{3}$. Para os demais caracteres em estudo, os dados sugerem que a seleção poderia ser efetuada nas últimas gerações, quando o valor genético da progênie seria mais precisamente determinado.

As correlações ambientes $\left(r_{A}\right)$, fenotípicas $\left(r_{F}\right)$ e genéticas $\left(r_{G}\right)$ entre produção de grãos e sete outros caracteres agronômicos para os cruzamentos entre Alondra $\mathrm{S}-46$ e três cultivares nacionais de porte alto encontram-se no quadro 4.

QUADRO 4. Correlações ambientes $\left(r_{A}\right)$, fenotípicas $\left(r_{F}\right)$ e genéticas $\left(r_{G}\right)$ entre produção de grăos e sete outros caracteres agronômicos para cruzamentos de trigo envolvendo o cultivar Alondra $\mathrm{S}-46$, de origem mexicana, com alto potencial produtivo, e três cultivares brasileiros

\begin{tabular}{|c|c|c|c|c|}
\hline $\begin{array}{l}\text { Caráter correlacionado } \\
\text { com produção de grãos }\end{array}$ & & $\begin{array}{c}\text { Alondra } \\
\mathrm{S}-46 \times \mathrm{BH}-1146\end{array}$ & $\begin{array}{l}\text { Alondra } \\
\text { S-46 x IAC-5 }\end{array}$ & $\begin{array}{c}\text { Alondra } \\
\mathrm{S}-46 \times \mathrm{C}-3\end{array}$ \\
\hline Comprimento da espiga & $\begin{array}{l}r_{A} \\
r_{F} \\
r_{G}\end{array}$ & $\begin{array}{l}0,034 \\
0,171 * \\
0,675\end{array}$ & $\begin{aligned} 0,322 * * \\
0,277 \% \\
>1,00\end{aligned}$ & $\begin{aligned} & 0,645 * * \\
& 0,360 * \\
> & 1,00\end{aligned}$ \\
\hline Espiguetas/espiga & $\begin{array}{l}r_{A} \\
r_{F} \\
r_{r_{r}}\end{array}$ & $\begin{array}{r}0,209 \\
-0,068 \\
-0,510\end{array}$ & $\begin{array}{r}0,010 \\
-0,026 \\
-0,131\end{array}$ & $\begin{array}{r}0,217 \\
0,022 \\
-0,286\end{array}$ \\
\hline Grãos/espiga & $\begin{array}{l}\mathrm{r}_{\mathrm{A}} \\
\mathrm{r}_{F} \\
\mathrm{r}_{\mathrm{r}}\end{array}$ & $\begin{aligned} & 0,368 * * \\
& 0,486 * * \\
> & 1,00\end{aligned}$ & $\begin{aligned} & 0,569 \% \\
& 0,483^{*} ; \\
> & 1,00\end{aligned}$ & $\begin{aligned} & 0,566 * \\
& 0,645 * \\
&> 1,00\end{aligned}$ \\
\hline Grãos/espigueta & $\begin{array}{l}r_{A} \\
r_{F} \\
r_{G}\end{array}$ & $\begin{aligned} & 0,334 * * \\
& 0,470 * * \\
> & 1,00\end{aligned}$ & $\begin{aligned} & 0,577^{*}: \\
& 0,415^{*} \\
> & 1,00\end{aligned}$ & $\begin{aligned} & 0,444 * * \\
& 0,593 * \\
> & 1,00\end{aligned}$ \\
\hline Peso de cem grãos & $\begin{array}{l}\mathbf{r}_{\mathrm{A}} \\
\mathbf{r}_{\mathrm{F}} \\
\mathbf{r}_{\mathrm{r}}\end{array}$ & $\begin{aligned} & 0,404 * * \\
& 0,347 * * \\
> & 1,00\end{aligned}$ & $\begin{aligned} & 0,220 \\
& 0.533 * * \\
> & 1,00\end{aligned}$ & $\begin{aligned} & 0,368 * * \\
& 0,461 * \\
> & 1,00\end{aligned}$ \\
\hline Altura da planta & $\begin{array}{l}\mathrm{r}_{\mathrm{A}} \\
\mathrm{r}_{\mathrm{F}} \\
\mathrm{r}_{\mathrm{G}}\end{array}$ & $\begin{aligned} & 0,456^{* *} \\
& 0,285^{* *} \\
> & 1,00\end{aligned}$ & $\begin{aligned} & 0,550 * * \\
& 0,217 * * \\
> & 1,00\end{aligned}$ & $\begin{aligned} 0,567 * * \\
0,468 * * \\
>1,00\end{aligned}$ \\
\hline Espigas/planta & $\begin{array}{l}\mathbf{r}_{\mathrm{A}} \\
\mathbf{r}_{\mathrm{F}} \\
\mathbf{r}_{G}\end{array}$ & $\begin{aligned} & 0,887^{* *} \\
& 0,545^{* *} \\
> & 1,00\end{aligned}$ & $\begin{aligned} & 0,774 \\
& 0,594 \\
> & 1,00\end{aligned}$ & $\begin{aligned} & 0,767 * * \\
& 0,583 * * \\
> & 1,00\end{aligned}$ \\
\hline
\end{tabular}

* Significativo ao nivel de 5\%. ** Significativo ao nivel de $1 \%$.

As correlações fenotípicas entre a produção de grãos e os demais caracteres agronômicos foram positivas e altamente signifį́ativas ao nível 
de $1 \%$, exceto entre a produção e o comprimento da espiga para a população Alondra S-46 x BH-1146, que foi positiva e significativa ao nível de $5 \%$, e para as populações Alondra S-46 x BH-1146, Alondra S-46 x IAC-5 e Alondra S-46 x C-3, onde as correlações fenotípıcas entre produção e número de espiguetas por espiga foram não-significativas.

No quadro 5 encontram-se as correlações ambientes $\left(r_{A}\right)$ e fenotípicas $\left(r_{F}\right)$ entre o comprimento da raiz medida após 72 hcras em solução nutritiva normal seguida de um tratamento de 48 horas em solução nutritiva, contendo $6 \mathrm{mg} /$ litro de $\mathrm{Al}^{3 \div}$, e produção de grãos, altura das plantas e número de grãos por espigueta (fertilidade da espiga), para os cruzamentos de trigo envolvendo o cultivar Alondra S-46, sensivel ao $\mathrm{Al}^{3+}$, e três cultivares tolerantes.

QUADRO 5. Correlações ambientes $\left(r_{A}\right)$ e fenotípicas $\left(r_{F}\right)$ entre o comprimento da raiz, medida após 72 horas em solução nutritiva normal, seguida de um tratamento de 48 horas em solução nutritiva contendo $6 \mathrm{mg} /$ litro de $\mathrm{A}_{1}{ }^{3+}$ e três outros caracteres agronômicos para os cruzamentos de trigo envolvendo o cultivar Alondra S-46, sensivel ao $\mathrm{Al}^{3+}$, e três cultivares brasileiros

\begin{tabular}{lcccc}
\hline $\begin{array}{l}\text { Caráter correlacionado } \\
\text { com comprimento da raiz }\end{array}$ & & $\begin{array}{c}\text { Alondra } \\
\text { S-46 }\end{array}$ & $\begin{array}{c}\text { Alondra } \\
\text { S-46 } \times \text { IAC-5 }\end{array}$ & $\begin{array}{c}\text { Alondra } \\
\text { S-46 x C-3 }\end{array}$ \\
\hline Produção de grãos & $\mathrm{r}_{\mathrm{A}}$ & 0,074 & 0,065 & 0,235 \\
& $\mathrm{r}_{\mathrm{F}}$ & 0,045 & $-0,040$ & 0,157 \\
Altura da planta & $\mathrm{r}_{\mathrm{A}}$ & $0,255^{*}$ & 0,046 & 0,194 \\
& $\mathrm{r}_{\mathrm{F}}$ & $-0,072$ & $0,187^{*}$ & 0,121 \\
Grãos/espigueta & $\mathrm{r}_{\mathrm{N}}$ & $-0,144$ & 0,136 & 0,124 \\
& $\mathrm{r}_{\mathrm{F}}$ & 0,099 & 0,032 & 0.151
\end{tabular}

* Significativo ao nível de $5 \%$.

A freqüência de distribuição para número de grãos por espigueta e altura das plantas das três populações $F_{2}$ estudadas em relação à tolerância ao $\mathrm{Al}^{3+}$ em solução nutritiva está representada na figura 1.

Nos cruzamentos estudados, a tolerância ao alumínio não foi associada com altura (com exceção da correlação fenotípica no cruzamento Alondra S-46 x IAC-5), produção de grãos e número de grãos por espigueta. Considerando essas correlações e pela figura 1 , verifica-se que seria possível selecionar, nas populações segregantes em estudo, plantas tolerantes ao alumínio, de porte médio, com maior fertilidade da espiga, com 0 potencial produtivo do cultivar Alondra S-46, que seriam adaptadas à maioria dos solos ácidos existentes nas regiōes tritícolas brasileiras. 
PLANTAS TOLERANTES A $6 \mathrm{mg} / \mathrm{l}$ DE $A l^{3+}$

$\square$ PLANTAS SENSIVEIS A $6 \mathrm{mg} / \mathrm{l}$ DE $A \mathrm{l}^{3+}$
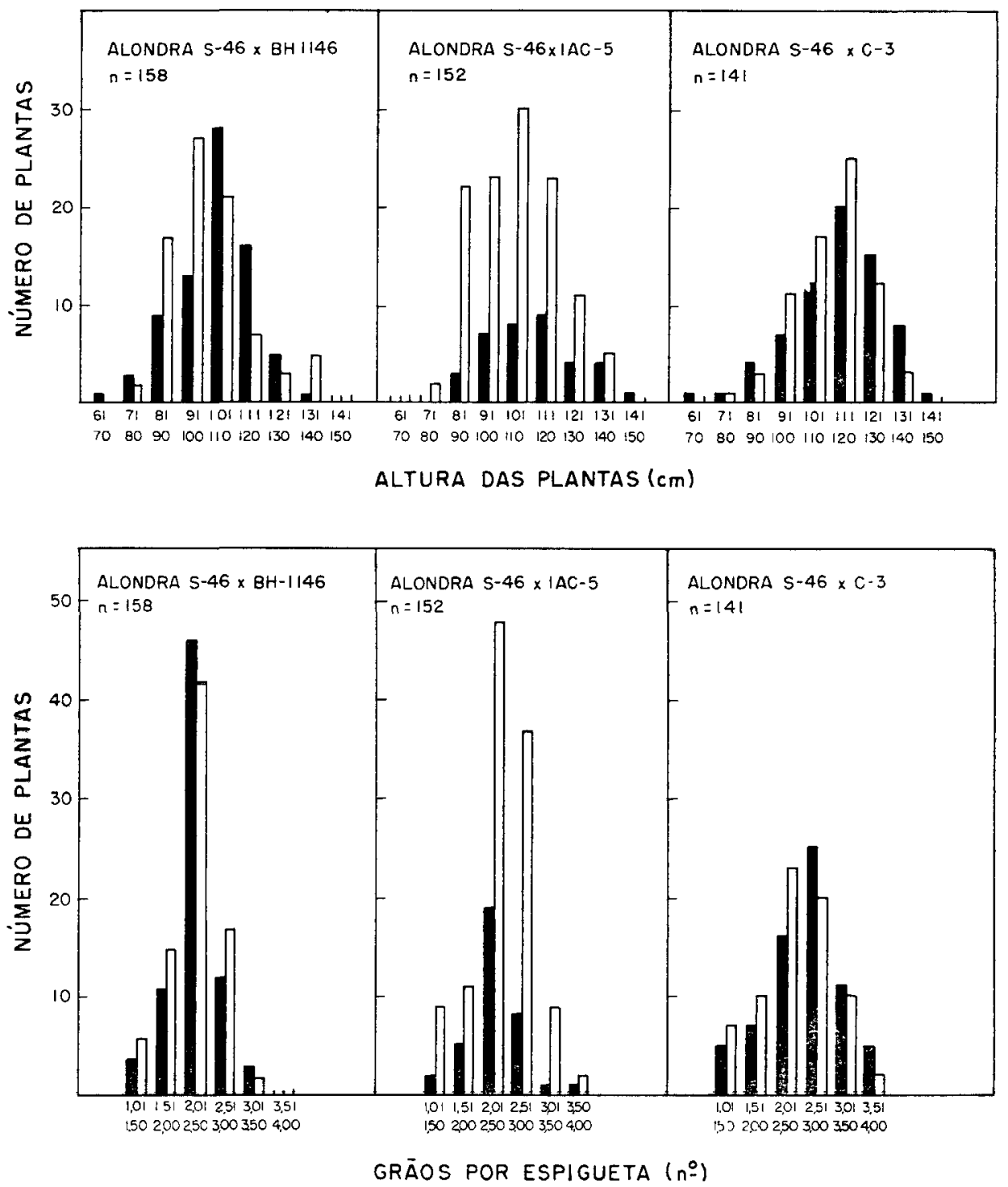

FIGURA 1. Frequiência de distribuição do número de grãos por espigueta e da altura das plantas das gerações $F$., dos cruzamentos entre Alondra-S-46, cultivar de trigo de origem mexicana de alto potencial produtivo, e três cultivares brasileiros. 


\section{SUMMARY}

\section{WHEAT BREEDING.}

\section{HERITABILITY ESTIMATES AND ASSOCIATIONS OF TOLERANCE TO ALUMINUM TOXICITY AND GRAIN YIELD WITH OTHER AGRONOMIC CHARACTERISTICS IN WHEAT}

High grain yield potential, and Al sensitive cultivar Alondra S-46 was crossed with standard height, low grain yield potential, Al tolerant cultivars IAC-5, BH-1146 and C-3. Parents, $F_{1}$ 's, $F_{\text {, }}$ 's and reciprocal backcrosses were tested for their seedling reaction to $6 \mathrm{ppm}$ of $\mathrm{Al}^{3}+$ in nutrient solution. Grain yield, plant height, number of spikes per plant, number of spikelets per spike, number of grains per spike, number of grains per spikelet, 100-grain-weight and spike length were determined for the same populations at maturity. Narrow sense keritability estimates were high for spike length, number of grains per spike, 100-grain-weight, and plant height; moderate for number of spikes per plant and number of spikelets per spike; and low for the rest of the agronomic characteristics under study. Additive effects were the main source of genetic variation for spike length, plant height, number of grains per spike and 100-grain-weight. Grain yield of the studied populations was significantly correlated with all the agronomic characteristics under study except the number of spikelets per spike. Tolerance to Al3+ toxicity was not associated with plant height (except for the population from the cross Alondra S-46 $x$ IAC-5), grain yield and number of grains per spikelet (spike fertility). The results suggested that there is a possibility of selecting plant types that combine $\mathrm{Al}^{3}+$ tolerance, semi-dwarf height levels and high yield potential, to be grown on acid soils.

\section{REFERENCIAS BIBLIOGRAFICAS}

1. CAMARGO, C.E.O. Melhoramento do trigo. VIII. Associações entre produção de grãos e outros caracteres agronômicos em populações híbridas de triğo envolvendo diferentes fontes de nanismo. Bragantia, Campinas, 43(2):541-552, 1984.

2.

; KRONSTAD, W.E.; METZGER, R. Parent-progeny regression estimates and associations of height levels with aluminum toxicity and grain yield in wheat. Crop Science, 20:355-358, 1980.

3. — OLIVEIRA, O.F. Melhoramento do trigo. II. Estudo genético de fontes de nanismo para a cultura do trigo. Bragantia, Campinas, 40:7791, 1981.

4.

Melhoramento do trigo. V. Estimativas das herdabilidades e correlações entre altura, produção de grãos e outros caracteres agronômicos em trigo. Bragantia, Campinas, 42:131-148, 1983.

5. —_ Tolerância de cultivares de trigo a diferentes niveis de aluminio em solução nutritiva e no solo. Bragantia, Campinas, 40:21-31, 1981.

6. FALCONER, D.S. Introduction to quantitative genetics. New York, Ronald Press, 1970. 365p.

7. FONSECA, S. \& PATTERSON, F.L. Yield components, heritabilities and interrelationships in winter wheat (Triticum aestivum L.). Crop Science, 8:614-617, 1968.

8. FOY, C.D.; ARMINGER, W.H.; BRIGGLE, L.W.; REID, D.A. Differential aluminum tolerance of wheat and barley varieties in acid soils. Agronomy Journal, 57:413-417, 1965. 
9. JOHNSON, V.A.; BIFVER, K.J.; HAUNOLD, A.; SCHMIDT, J.W. Inheritance of plant height, yield of grain, and other plant and seed characteristics in a cross of hard red winter wheat (Triticum aestivum L.). Crop Science, 6:336-338, 1966.

10. KETATA, H.; EDWARDS, L.H.; SMTTH, E.L. Inheritance of eight agronomic characters in a winter wheat cross. Crop Science, 16:19-22, 1976.

11. MOORE, D.P.; KRONSTAD, W.E.; METZGER, R. Screening wheat for aluminum tolerance. In: WORKSHOP ON PLANT ADAPTATION TO MINERAL STRESS IN PROBLEM SOILS, Beltsville, Maryland, 1976. Proceedings. p.287-295.

12. PEPE, J.F. \& HEINER, R.F. Plant height protein percentage, and yield relationship in spring wheat. Crop Science, 15:793-797, 1975.

13. SILVA, A.R. Application of the genetic approach to wheat culture in Brazil. In: WORISSHOP ON PLANT ADAPTATION TO MINERAL STRESS IN PROBLEM SOILS, Beltsville, Maryland, 1976. Proceedings. p.223-231. 